Res Publica Revista de Historia de las Ideas Políticas

ISSN: $1131-558 \mathrm{X}$

\title{
Sobre la importancia del plusvalor marxiano como preámbulo a toda reflexión ecológica
}

\author{
Eva Blaya Melchor ${ }^{1}$
}

Recibido: 15-01-2021 / Aceptado: 25-04-2021

Resumen. Dado que seguramente uno de los temas de nuestro tiempo sea la filosofía ecológica, este artículo tiene por objeto analizar la categoría marxiana de plusvalor a fin de proporcionar un marco a dicha reflexión. Esta categoría pone de manifiesto tanto la lógica que rige el movimiento de la sociedad moderna capitalista, como lo que se oculta tras ella, a saber, el socavamiento de la fuerza de trabajo, de los seres vivos y su entorno. Así pues, tras una lectura atenta de las cinco primeras secciones del Libro I de El Capital donde alumbraremos las nociones de valor, plustrabajo, plusproducto, plusvalor absoluto y plusvalor relativo, buscaremos el rendimiento que éstas pueden tener para comprender los problemas sociales y ecológicos que adolece nuestro presente, dejando sentadas así las bases para una filosofía de la ecología a la altura de nuestros días.

Palabras clave: Marx; plusvalor; plusproducto; ecología; ecosocialismo.

\section{[en] On the Importance of Marxian Category Surplus Value as a Preamble to All Ecological Reflection}

Abstract. It may be agreed that ecology is a current topic of reflection in contemporary Philosophy, so this article attempts to show how the Marxian category surplus value can offer a deep insight into the causes of the present ecological crisis. That category not only exhibits the economic law of motion of modern society, but also what is hidden behind it, namely, predation of labour power, living things and environment. After reading the first five parts of Capital and explaining Marxian categories such as value, surpluslabor, plusproduct, relative and absolute surplusvalue, we will show how they help us think about both current social and ecological problems, and why they can guide a truly effective ecological reflection.

Keywords: Marx; Surplus Value; Surplus Product; Ecology; Ecosocialism.

Sumario. I. Sobre el valor. II. Sobre el plusvalor. III. Sobre el plusvalor, el plustrabajo y el plusproducto. IV. Sobre el plusvalor absoluto y el plusvalor relativo. V. Sobre el rendimiento de las categorías marxianas para una filosofía ecológica. VI. Conclusiones. Bibliografía.

Cómo citar: Blaya Melchor, E. (2021). Sobre la importancia del plusvalor marxiano como preámbulo a toda reflexión ecológica. Res Publica. Revista de Historia de las Ideas Politicas, 24(2), 249-258.

\section{Sobre el valor}

Si alguien cree que puede resolver una seria cuestión medioambiental sin afrontar siquiera cómo se crean y producen los valores de las mercancías y con qué consecuencias se está engañando a sí mismo.

(Harvey, Guía de El Capital)

Tal y como recomienda la cita que abre el presente apartado, parece obligado explicar someramente qué puede querer decir valor. Semejante noción invita al lector o lectora a adentrarse en un ámbito problemático, no solo porque se cuentan con hasta cuatro versiones de la teoría del valor escritas por Marx, sino porque además existen numerosas polémicas dentro de la propia tradición marxiana en torno a su significado y sus ineludibles consecuencias económicas, políticas y sociales. Así pues, queremos empezar poniendo de manifiesto que nuestra lectura del valor se encuentra mediada por autores como Michael Heinrich, David Harvey, César Ruiz y Clara Ramas; si bien nuestro interés se centra en buscar el rendimiento de las nociones marxianas a la hora de alumbrar los problemas sociales y ecológicos que adolece nuestro presente.

\footnotetext{
Universidad Complutense de Madrid

eblaya01@ucm.es

2 De acuerdo con C. Ruiz Sanjuán, Historia y sistema en Marx, Madrid, Siglo XXI, 2019, pp. 178 ss., creemos que la forma más adecuada de acercarnos a la noción de valor es partiendo de El capital, obra considerada por el propio Marx como su verdadero legado intelectual, resultando siempre enriquecedor acudir a los manuscritos preparatorios de El Capital para esclarecer o completar algunas explicaciones.
} 
Entender qué quiere decir valor nos coloca al comienzo de la primera sección de El Capital ${ }^{2}$, donde se expresa que lo específico y característico de la sociedad capitalista es el intercambio generalizado de mercancías. En ese intercambio observamos que las mercancías no solo tienen una utilidad (un valor de uso), sino también un valor de cambio. Ello quiere decir que las mercancías, por muy dispares que sean, parecen ser conmensurables, pues se intercambian siempre que se respete la proporción que corresponda (p. ej.: en un kilo de patatas por un kilo de naranjas la proporción es 1:1). Ahora bien, Marx matiza que "sin igualdad de esencias no se podría establecer una relación recíproca"3, o lo que es igual, para que las mercancías dispares puedan ser conmensurables $-\mathrm{y}$, por tanto, intercambiables- deben de tener algo en común. Así pues, "el valor de cambio únicamente es el modo de expresión o forma de manifestarse de un contenido diferenciable de él"4, a saber, el valor. El valor es, pues, lo que tienen en común todas las mercancías ${ }^{5}$. Más concretamente, lo que tienen en común todas las mercancías en condiciones capitalistas es que son productos del trabajo, pero no de este o aquel trabajo concreto, sino de trabajo abstracto ${ }^{6}$.

Tenemos que empezar a pensar que la noción de trabajo abstracto se refiere, ciertamente, a una abstracción, pero una abstracción que se realiza, acaece o tiene lugar en el intercambio. Para comprender el alcance de estas afirmaciones, reflexionemos sobre la siguiente situación:

Imaginemos que un trabajador invierte mucho tiempo en su labor, ¿ello hace que su mercancía sea más valiosa en el mercado? Ciertamente la respuesta es negativa. Para Marx ello quiere decir que la magnitud del valor, lo que constituye el valor, es el tiempo de trabajo socialmente necesario. El trabajo socialmente necesario es

el requerido para producir un valor de uso cualquiera, en condiciones normales de producción vigentes en una sociedad y con el grado social medio de destreza e intensidad de trabajo (...) Es solo el tiempo de trabajo socialmente necesario para la producción de un valor de uso lo que determina su magnitud de valor ${ }^{7}$.

Ello quiere decir que en condiciones capitalistas no es hasta que el aludido trabajador llega al mercado cuando descubre en qué medida su tiempo de trabajo gastado individualmente corresponde al tiempo de trabajo socialmente necesario. $\mathrm{O}$, si se quiere, no es hasta que llega al mercado cuando repara en que fue un trabajador más lento que los demás. Y no solo eso, sino que también descubrirá en qué medida su trabajo concreto vale

K. Marx, El capital (Libro I), Ciudad de México, Siglo XXI, 2019, p. 73 .

Ibidem, p. 45 , nota al pie b.

Nótese, como dice D. Harvey, Guía para leer el Capital Libro I, Madrid, Akal, 2016, p. 113, que "el valor no es una categoría universal, sino algo único en el capitalismo".

6 Tal y como explica M. Postone, Tiempo, trabajo y dominación social, Madrid, Marcial Pons, 2006, p. 143, si bien una mercancía "como valor de uso particular es el producto de un trabajo concreto particular; como valor, es objetivación de trabajo humano abstracto". Marx, op. cit., p. 48. como parte del trabajo social global (en qué medida su trabajo concreto es socialmente útil para otros) ${ }^{8}$.

Lo que importa retener de todo esto es que si el trabajo abstracto es aquel que constituye el valor de las mercancías, cuando se intercambian mercancías lo que en el fondo se están intercambiando son cantidades equivalentes de trabajo humano simple, abstracto y socialmente necesario. Y no solo eso, sino que el trabajo abstracto, como dice Heinrich, es una relación de validez constituida en el cambio. Esto es, si el trabajo abstracto es una abstracción que acaece en el intercambio, entonces el valor no es una propiedad que tengan las mercancías aisladamente. Piénsese por un momento, no es posible "expresar en metros de tela el valor de los metros de tela" . El valor, nos dice Marx, "en contradicción directa con la objetividad sensorialmente grosera del cuerpo de las mercancías" 10 no puede ser aprehendido de ningún modo en una mercancía aislada, aunque parezca que son las mercancías las que poseen el valor como una propiedad objetiva que les correspondería incluso fuera de la relación de intercambio. No obstante, es en el intercambio donde el valor recibe una forma susceptible de ser aprehendida.

Es porque en condiciones capitalistas los productores de mercancías no se relacionan entre sí de manera inmediatamente social, sino por medio del intercambio generalizado de los productos de sus trabajos; por lo que se les aparecen "los caracteres sociales de [su] propio trabajo como caracteres objetivos de los productos mismos del trabajo y, por lo tanto, su relación social como una relación social entre objetos"11. Esto es, el valor es la "expresión palmaria de una sociabilidad que producen las personas, pero que no comprenden; es la expresión de relaciones entre personas, mediadas por cosas, pero entre personas al fin y al cabo" ${ }^{12}$. Si ello es así y a los individuos se les reflejan sus relaciones sociales como propiedades de las cosas, ello tendrá "como consecuencia que se establezca, a espaldas de los agentes sociales un poder autónomo al que se encuentran subordinados y cuyo movimiento no pueden controlar"'s.

El cuestionamiento en torno a las condiciones de posibilidad por las que una propiedad social como el valor puede aparecer como una propiedad objetiva de las cosas, nos lleva a los complejos pasajes en torno la forma de valor (en la sección primera, capítulo tercero del Libro I). Y es que en ellos se desvela la "apariencia que encanta y tergiversa el mundo capitalista por entero"14 y cuyo secreto se encuentra en la simple equivalencia: $x$ mercancía $A$ = y mercancía $B$.

Hemos comentado someramente dos de las tres reducciones que tienen lugar en el intercambio, cf. M. Heinrich, Crítica de la economía política: una introducción a El Capital de Marx, Madrid, Escolar y Mayo, 2008, p. 85 ss., así como también C. Fernández Liria y L. Alegre Zahonero, Marx desde cero: para el futuro que viene, Madrid, Akal, 2018, pp. 54 ss.

Marx, op. cit., p. 60.

$10 \quad$ Ibidem, p. 58.

11 G. Lukács, "La cosificación y la consciencia del proletariado", Historia y consciencia de clase (vol. 2), Barcelona, Grijalbo, 1969, p. 11.

12 C. Ramas San Miguel, Fetiche y mistificación capitalistas: la crítica de la economía politica de Marx, Madrid, Siglo XXI, 2018, p. 71.

13 C. Ruiz Sanjuán, op. cit., p. 371.

14 C. Ramas, op. cit., p. 196. 
Supongamos que la mercancía A se refiere a metros de tela y la mercancía B a chaquetas. Cuando expresamos que tantos metros de tela (x mercancía $A$ ) valen lo mismo (=) que tantas chaquetas (y mercancía B) estamos expresando el valor de la tela como una determinada cantidad de chaqueta. Es decir, estamos expresando el valor de los metros de tela relativamente. En efecto, que la mercancía A (la tela) se encuentre en forma relativa quiere decir que su valor se expresa en otra mercancía cuyo valor es equivalente, en este caso, chaquetas. Por tanto, la mercancía B (las chaquetas) se encuentra correlativamente en la forma de equivalente.

Ahora bien, si nos fijamos, el valor de los metros de tela "se refleja en el cuerpo de otra mercancía, en la objetividad de otro ente distinto"15. En efecto, las chaquetas, al encontrarse en la forma de equivalente, están proporcionando un cuerpo material -un valor de usopara la expresión del valor de otra mercancía. Esto es, el valor de uso chaqueta está encarnando trabajo que constituye valor -trabajo abstracto-. Ello quiere decir que parece que es la chaqueta la que posee por naturaleza la propiedad de ser valor, gracias a lo cual se puede vincular a ella la tela $-\mathrm{y}$ no que la chaqueta exprese el valor de la tela por encontrarse en una relación con ella-. En definitiva, y de acuerdo con Ramas, la mercancía en forma de equivalente, al ser la encarnación del valor de la mercancía en forma relativa, se transforma en la forma de aparición del valor. Es por la forma de equivalente como el valor parece pertenecer a las mercancías, incluso fuera de la relación de intercambio. Nótese pues, que no es una ilusión el que, bajo condiciones capitalistas, las cosas tengan propiedades sociales, lo que es falso es que tengan dichas propiedades automáticamente en cualquier contexto social.

Ahora bien, se podría argumentar que en el ejemplo que acabamos de comentar solo había una relación de equivalencia entre dos mercancías, a saber, la tela y la chaqueta. A ello lo llamará Marx forma simple de valor. Aquella expresión que permite establecer la equivalencia entre el valor de la tela e innumerables y heterogéneos equivalentes la bautizará como forma desplegada de valor. Asimismo, nombrará forma general de valor a la expresión del valor de todas mercancías (y no solo de la tela) en un único equivalente general. El hecho de que una clase específica de mercancía, por costumbre social, funcione como equivalente general le lleva a la forma de dinero.

Detengámonos por un momento, ¿cuántas veces no tendemos a pensar que el dinero tiene como propiedad natural el ser valioso? o ¿cuántas veces no tendemos a pensar que las mercancías son conmensurables por obra del dinero? Al igual que comentábamos en el ejemplo anterior que la chaqueta parecía poseer la propiedad de ser valor, cuando no hacía más que expresar el valor de la tela por encontrarse en una relación con ella; "la forma de dinero no es más que el reflejo, adherido a una mercancía, de las relaciones entre todas las demás mercancías"16. Esto es, las mercancías en tanto que valores o cristalizaciones de trabajo abstracto son con-

$\begin{array}{ll}15 & \text { Ibidem, p. } 198 . \\ 16 & \text { K. Marx, op. cit., p. } 110 .\end{array}$ mensurables, razón por la cual pueden medir sus valores en la misma mercancía específica (y ésta convertirse en la medida colectiva de valor). Así pues, con la forma de dinero tiene lugar "la fijación definitiva de [una] apariencia: una mercancía, una cosa, se convierte en la cristalización inmediata del valor y del trabajo abstracto humano, es decir, de una relación social"17.

Retengamos que Marx está defendiendo que el dinero no es un medio auxiliar que facilite, simplifique y agilice el intercambio, sino que "constituye un producto necesario del proceso de intercambio, en el cual se equiparan de manera efectiva y recíproca los diversos productos del trabajo y por consiguiente se transforman realmente en mercancías" ${ }^{18}$. Esto es, si bien la forma de valor es aquello sin lo cual las mercancías no pueden referirse unas a otras, la forma de dinero es aquella forma de valor que permite expresar el valor de todas las mercancías en un único equivalente general.

Ahora bien, el dinero tiene más funciones aparte de manifestar el valor de las mercancías, como, por ejemplo, ser medio de circulación ${ }^{19}$. Es porque las mercancías no pueden intercambiarse por sí mismas -explicará Marx con cierta ironía- por lo que necesitan de custodios o poseedores que actúen en tanto que categorías económicas personificadas y las intercambien ${ }^{20}$. Dicho intercambio, dicha metamorfosis, tendrá como intermediario al dinero, por lo que su forma será M-D-M: mercancía-dinero-mercancía. En este proceso observamos que "una mercancía comprada, [al ser] valor de uso para quien la compra, puede desaparecer de la circulación, [pero] el dinero no desaparece" ${ }^{21}$, sino que permanece continuamente en la esfera de la circulación. Tal vez si "el dinero es rueda de circulación para la mercancía, la mercancía lo es igualmente para el dinero" ${ }^{22}$.

\section{Sobre el plusvalor}

Terminábamos el apartado anterior comentando que la forma de dinero era la expresión autónoma requerida por la circulación simple de mercancías en tanto que forma más adecuada para expresar el valor de las mercancías. Sin embargo, esa autonomía del dinero exigida por la propia circulación simple no podía existir dentro de ella,

\footnotetext{
C. Ramas, op. cit., p. 203.

18 K. Marx, op. cit., p. 106.

19 Hay que matizar que Marx distingue tres, y no dos, funciones del dinero, a saber, medida de valores, medio de circulación y dinero real. El dinero real hace referencia la presentación de la mercancía dineraria en su corporeidad, a su presentación como existencia material de riqueza abstracta. El dinero real se subdivide, a su vez, en tres funciones: tesoro, medio de pago y dinero mundial. Somos conscientes de que comentar dichas subdivisiones, en especial el tesoro y el medio de pago, enriquecería la comprensión del tránsito del valor al plusvalor. No obstante, por motivos de espacio hemos decidido reducir la explicación del tránsito a lo que creemos que son sus elementos esenciales.

20 Que los poseedores de mercancías sean una personificación de una categoría económica quiere decir que sus motivos impulsores para actuar son expresión de una lógica que nada tiene que ver con su voluntad individual.

21 D. Harvey, op. cit., p. 71.

22 K. Marx, Elementos fundamentales para la crítica de la economía política, borrador 1857-1858 (Grundrisse vol. 1), Ciudad de México, Siglo XXI, 2007, p. 199.
} 
pues en tanto que medio de circulación era un intermediario fugitivo. Justamente por ello, nos preguntábamos al final del apartado anterior si había otra circulación donde el mediador no fuese el dinero, sino la mercancía (D-M-D). Ahora bien,

cambiar mercancía por mercancía tiene un sentido, en tanto las mercancías, aunque equivalentes como precios [suponiendo que se vendan a su valor], son cualitativamente distintas, y el cambio después de todo, satisface necesidades cualitativamente distintas. Por el contrario, cambiar dinero por dinero no tiene ningún sentido, a menos que se obtenga una diferencia cuantitativa, es decir, que se cambie menos por más, que se venda más caro de lo que se compre $^{23}$.

Esto es, la circulación D-M-D no tiene sentido alguno a menos que el dinero se acreciente (D-M-D'). Ahora bien, ¿y si la circulación simple de mercancías que hemos comentado hasta ahora no fuese una esfera autónoma, sino más bien un momento de un proceso subyacente "donde el dinero no fuese simplemente valor, sino forma autónoma y permanente de valor, dinero que tiene que mantenerse y acrecentarse"24? Esto es, quizá de lo que se trate con la misteriosa forma autónoma del dinero es de un cierto reingresar en la circulación, sin perder en ese movimiento su autonomía. En una palabra, las circulaciones M-D-M y D-M-D' no son más que “dos momentos esenciales de un todo único"25. Si ello es así, el acrecentamiento de dinero, esto es, la diferencia entre D'y D, recibirá el nombre de plusvalor; mientras que el todo único de ambas circulaciones recibirá el nombre de capital. De hecho, si nos fijamos en la circulación DM-D' vemos que mercancía y dinero son dos modos de existencia del valor. El valor es el verdadero sujeto de un proceso por el cual pasa constantemente de su forma de existencia particular (mercancía) a su forma de existencia general (dinero), experimentando, con ello, un cambio de magnitud. Se podría decir que estamos ante un sujeto automático que se auto valoriza, o, como nos dice Marx irónicamente, que ha obtenido la cualidad oculta de poner huevos de oro.

Ahora bien, la fórmula D-M-D' parece contradecir todo lo expuesto hasta ahora, pues por medio del intercambio de equivalentes no se puede obtener más valor (D') del que se arrojó (D) a la circulación ${ }^{26}$. Ahora bien, ¿y si encontrásemos en el mercado una mercancía cuyo valor de uso tuviese la propiedad de ser fuente de valor? En ese caso, el uso de esa mercancía generaría valor: más valor del que ella cuesta. Dicha mercancía es la fuerza de trabajo ${ }^{27}$.

\section{Ibidem, pp.135-136.}

M. Heinrich, op. cit., p.121.

25 K. Marx, Elementos fundamentales para la crítica de la economía politica, op. cit., p. 132.

26 Conviene aclarar que el hecho de que los vendedores vendan sus mercancías por encima de su valor, o que los compradores las compren por debajo de su valor, no permite explicar la formación del plusvalor.

27 El ser humano al encontrarse en unas circunstancias histórico-determinadas donde es propietario de sí y donde se ve libre de propiedad material, nos dice Marx en El capital, op. cit., p. 327, "se presta voluntariamente, es decir, se ve socialmente obligado a vender todo el tiempo de su vida activa, su capacidad misma de trabajo, por el
Así pues, el poseedor de medios de producción (el capitalista) se encuentra en el mercado con que una mercancía muy peculiar está a la venta, a saber, el conjunto de facultades físico-mentales que existen en la corporeidad viva de un ser humano y que son susceptibles de, puestas a trabajar, dar lugar a valores de uso. El capitalista compra dicha mercancía a su valor, el cual se corresponde con el valor de los medios de vida necesarios para la subsistencia de su poseedor (el trabajador). El capitalista usa su mercancía, y tiene todo el derecho a hacerlo: pone la fuerza de trabajo a trabajar. Ahora bien, la clave residirá en que el mantenimiento de la fuerza de trabajo y su rendimiento son dos magnitudes diferentes. La primera determina su valor de cambio, a saber, el valor de los medios de vida necesarios para la subsistencia del trabajador; no obstante, la segunda determina su valor de uso. En efecto, que el valor equivalente a los medios necesarios para la subsistencia del trabajador se obtenga en media jornada laboral no impide a dicho trabajador trabajar durante la jornada completa. De hecho, es así como el capitalista, después de haber puesto a trabajar a la fuerza de trabajo, reingresará en el mercado, pero esta vez como vendedor del valor de uso resultante del trabajo realizado por el trabajador. Y si puede hacer ello es porque como comprador de la fuerza de trabajo le pertenece ésta y su uso. Sabemos que el valor de dicho valor de uso sobre el que el trabajador ha gastado su fuerza se determinará en el cambio, pero una cosa es segura: habrá una diferencia entre el valor de la fuerza de trabajo y el valor que el trabajador individual ha producido y se ha cristalizado en ese valor de uso que será vendido. Esa diferencia es el plusvalor, y precisamente por ello surge y no surge de la esfera de la circulación: surge en tanto que se compra una mercancía en el mercado (fuerza de trabajo), y no surge en tanto que con ella se inicia un proceso de valorización en la esfera de la producción. Lo que importa destacar es que en la esfera de la circulación se manifiesta que el poseedor de medios de producción compra y luego vende, y en ese movimiento se incrementa su dinero (D-M-D’).

\section{Sobre el plusvalor, el plustrabajo y el plusproducto}

Terminábamos el apartado anterior comentando que el proceso por el cual el valor pasaba de su existencia particular como mercancía a su existencia general como dinero, implicaba un cambio de magnitud al que denominábamos plusvalor. Tal vez ahora estemos en condiciones de reparar en que esa cualidad oculta de poner huevos de oro constituye un fin en sí en el sentido de un proceso carente de medida. Esto es, el proceso de valorización es un movimiento ilimitado,

precio de sus medios de subsistencia habituales". Por medio explicaciones como esta, tal y como evidencia C. Ruiz Sanjuán, op. cit., p. 372, "Marx disuelve el carácter de naturaleza que [en este caso puede presentar una noción como fuerza de trabajo] y muestra que es el resultado de unas relaciones sociales que los hombres establecen entre sí dentro de un modo de producción históricamente determinado". 
y aquello que lo posibilita se encuentra en la esfera de la de la producción, en el uso de la fuerza de trabajo. Dicho más concretamente, lo que posibilita el proceso ilimitado de valorización se encuentra en un ámbito donde la fuerza de trabajo opera sobre materiales proporcionados, en último término, por el entorno natural $^{28}$.

Si recordamos, decíamos en el apartado anterior que el trabajador solo tendría que trabajar durante un número de horas al día para reproducir el equivalente en valor de su fuerza de trabajo, pero ello no impedía que éste pudiese trabajar más horas para el capitalista. Así pues, no debe de resultar extraño que Marx comience a hablar de trabajo necesario y plustrabajo. Trabajo necesario se refiere al tiempo que necesita el trabajador para reproducir el valor equivalente de su fuerza de trabajo ${ }^{29}$, mientras que la noción de plustrabajo se refiere al trabajo realizado por el trabajador para el capitalista fuera de las necesidades de su reproducción, y, por tanto, a un tiempo de trabajo realizado por el obrero que no le es pagado, razón por la cual en el proceso de producción se inicia un proceso de valorización.

Si todo ello es así, denominaremos jornada laboral a "la suma del trabajo necesario y del plustrabajo, de los lapsos en que el obrero produce el valor sustitutivo de su fuerza de trabajo y el plusvalor"30. Conviene retener que bajo condiciones capitalistas "el trabajo necesario no puede ser sino una parte de la jornada laboral del obrero y esta nunca puede reducirse a ese mínimo"31. Esto es, en el caso de reducirse la jornada laboral a ese mínimo no habría plusvalor y, a la postre, no habría ganancia para el capitalista. Asimismo, hay que reparar en que la jornada tiene un límite máximo físico, y es que durante un día de 24 horas un ser humano solo puede gastar una cantidad determinada de fuerza vital. Ello se debe a que una parte del día debe reposar, dormir, satisfacer otras necesidades como alimentarse, asearse, vestirse... En una palabra, parece estar claro que la jornada laboral debe durar menos de 24 horas, pero ¿cuánto menos? Esta será la clave. Y es que "de la naturaleza del intercambio mercantil no se desprende límite alguno de la jornada laboral, y por tanto límite alguno del plustrabajo"32, de manera que, si el único impulso vital del capital es valorizarse, absorber mayor masa posible de plustrabajo, no debe extrañarnos que busque prolongar e intensificar la jornada laboral.

No obstante, hay que reconocer que "el plustrabajo y el trabajo necesario se confunden en un todo" ${ }^{33}$, es decir, no saltan a la vista. $Y$ es que cuando estamos trabajando no suena una sirena que nos indique que se ha terminado el tiempo de trabajo que dedicamos

28 Marx en El Capital, op. cit., pp. 52-53 comenta, por medio de la metáfora de género de William Petty, que los valores de uso, estrictamente hablando, son el resultado de la combinación de dos elementos: el material proporcionado por la naturaleza (madre) y el trabajo (padre).

29 La noción de trabajo necesario no debe confundirse con la noción de trabajo abstracto como medida de valor comentado en el primer apartado.

$30 \quad$ Ibidem, p. 276.

Ibidem, p. 278.

Ibidem, p. 282

Ibidem, p. 284. a producir un equivalente en valor de nuestra fuerza de trabajo, para empezar a trabajar para el capitalista gratuitamente. Ello se debe a que "el capital encubre la relación de dominación bajo el aspecto del trabajo asalariado [de manera que el] plustrabajo que el obrero entrega al capital es percibido como un contrato justo de intercambio igual" ${ }^{34}$. La dominación o coerción capitalista queda oculta tras el velo de la voluntariedad, en el libre intercambio del mercado y en la forma del libre contrato entre obrero y capitalista. Así pues, lo que debemos retener es que, pese a que esa sirena de la que hablábamos unas líneas más arriba sea inaudible, en ningún momento deja de ser real.

[Cuando] el obrero proyecta más allá de los límites del trabajo necesario, no cabe duda de que le cuesta trabajo, gasto de fuerza laboral, pero no genera ningún valor para él. Genera plusvalor, que le sonríe al capitalista con todo el encanto cautivante de algo creado de la nada. (...) Así como para comprender el valor en general lo decisivo es concebirlo como (...) trabajo objetivado, para comprender el plusvalor es necesario concebirlo como (...) nada más que plustrabajo objetivado ${ }^{35}$.

Si el filósofo considera que la mejor manera de comprender el plusvalor es como plustrabajo objetivado, tal vez debamos empezar a hablar de plusproducto y producto necesario. Y es que habrá una parte del producto elaborado por el trabajador en la que se represente el plustrabajo y otra en la que se represente el trabajo necesario $^{36}$.

Decíamos, pues, que el trabajador vende su fuerza de trabajo al capitalista y trabaja para él durante su jornada laboral. En dicha jornada el trabajador produce mercancías, pongamos por caso, zapatos. Salta a la vista que en dichos zapatos no vemos una línea que separe la parte de éstos que fue elaborada en el tiempo de plustrabajo de la que fue elaborada en el tiempo de trabajo necesario, como tampoco oíamos antes aquella sirena. No obstante, de su invisibilidad no se sigue su irrealidad. Una vez que haya finalizado la jornada laboral del obrero, el capitalista para el cual éste trabaja reingresará en el mercado y esperará tener suerte para convertir esos zapatos en su equivalente en dinero. Si nos estamos deteniendo en esto es porque el "plusvalor no es dinero contante y sonante, sino un plusproducto que tiene que ser vendido, es decir, transformado en dinero en el mercado" ${ }^{37}$. Repárese, entonces, en que la producción en condiciones capitalistas podrá dar lugar a una pluralidad y heterogeneidad de mercancías inauditas, pero si éstas se producen será en la medida en que son plusvalor, plusvalor con la forma de una mercancía concreta, plusproducto: "la producción capitalista no solo es producción de mercancía, es, en esencia, producción de plusvalor" ${ }^{38}$. Ello

\footnotetext{
4 E. Dussel, La producción teórica de Marx. Un comentario a los Grundrisse, Ciudad de México, Siglo XXI, 1985, p. 165.

5 K. Marx, El capital, op. cit., pp. 260-261.

36 K. Marx aclara en ibidem, p. 625: "el plusproducto no brota del trabajo humano como algo innato, sino bajo condiciones capitalistas: en ningún caso su plusproducto brotaría de una cualidad oculta, innata al trabajo humano".

37 C. Fernández Liria y L. Alegre, op. cit., p. 210.

38 K. Marx, El capital, op. cit., p. 616.
} 
nos hace matizar enormemente una de las primeras oraciones abordadas en este escrito, y es que si la riqueza en condiciones capitalistas aparece bajo la forma de una inmensa acumulación de mercancías es en la medida en que éstas son plusproducto.

\section{Sobre el plusvalor absoluto y el plusvalor relativo}

Explicábamos en el apartado anterior las nociones de $p l u s$ producto y plustrabajo, y enfatizábamos en que desde la perspectiva del capitalista -en tanto que personificación de una categoría económica- el objetivo era conseguir el mayor y más intenso gasto posible de la fuerza de trabajo, pues así más proporción de plusproducto habría en sus mercancías, y mayor sería la ganancia en caso de vender dichas mercancías (D-M-D'). Si el capital es el proceso por medio del cual el valor se valoriza, ahora debemos poner de manifiesto que existen dos posibilidades:

Denomino plusvalor absoluto al producido mediante la prolongación de la jornada laboral; por el contrario, al que surge de la reducción del tiempo de trabajo necesario y del consiguiente cambio en la proporción de magnitud que media entre ambas componentes de la jornada laboral, lo denomino plusvalor relativo ${ }^{39}$.

La noción de plusvalor absoluto gira en torno a la extensión de la jornada laboral. Dada una jornada laboral de ocho horas, donde cuatro horas se corresponden con el tiempo de trabajo necesario y cuatro horas con el tiempo de plustrabajo, si se desea producir más plusvalor, se podrá alargar dicha jornada laboral hasta, por ejemplo, las diez horas. En ese caso, caeterīs pāribus, el tiempo de trabajo necesario seguiría siendo de cuatro horas, mientras que el de plustrabajo sería de seis. Así, tendría lugar una "disminución del tiempo necesario relativa (o proporcional) al aumento del tiempo de plustrabajo" $"$.

Ahora bien, existe otra posibilidad complementaria a la anterior de obtener plusvalor, a saber, que tenga lugar una disminución absoluta del tiempo necesario de la jornada laboral. Ello puede darse por medio de la cooperación, y es que no solo el "trabajo se efectúa mejor y más rápidamente mediante la cooperación de muchos brazos" "41, sino que se llega a resultados a los que no podrían llegar individuos aislados, más que en un tiempo mucho más prolongado. Complementariamente, se puede reducir el tiempo necesario dividiendo el trabajo, pues "las distintas operaciones de un proceso de trabajo [pueden] quedar recíprocamente disociadas y cada operación parcial adquirir, en manos de un obrero parcial, la forma más adecuada posible"42.

\footnotetext{
Ibidem, p. 383

40 E. Dussel, Hacia un Marx desconocido. Un comentario de los manuscritos 61-63, Ciudad de México, Siglo XXI, 1988, p. 91.

${ }^{41}$ K. Marx, El capital, op. cit., p. 397, nota al pie 12.

42 Ibidem, p. 415. Quizá sería interesarse reflexionar, como nos dice Marx en ibidem, p. 515, sobre si la otra cara del trabajo mecánico fuese que agrede "de la manera más intensa el sistema nervioso, reprime el juego multilateral de los músculos, y confisca toda actividad libre, física e intelectual del obrero".
}

Más allá de las formas organizativas que acabamos de comentar (i.e. la cooperación y la división del trabajo) también se puede reducir el tiempo de trabajo necesario mediante una revolución técnica del proceso de trabajo, esto es, mediante una revolución en el modo de producción, de la mano de la maquinaria, por ejemplo. Y es que una máquina ayuda a producir a más velocidad: más mercancías en menos tiempo. Ello abre la posibilidad de que un capitalista produzca más que el resto de los capitalistas del mismo sector, emplee menos tiempo del socialmente necesario para la producción de sus mercancías, y al haber sustituido a parte de su fuerza de trabajo por dicha maquinaria sus costes sean menores. Es la esperanza de este beneficio extra lo que motiva al capitalista individual a innovar o ser tecnológicamente dinámico ${ }^{43}$.

Ahora bien, hay que reconocer que la incorporación de la maquinaria al proceso productivo hace que "para vender los productos de una jornada laboral [se necesite] una demanda duplicada, o sea, un mercado doblemente grande" ${ }^{44}$. Y es que dichas mercancías solo podrán conquistar un mercado más amplio si reducen sus precios. Aunque el capitalista reduzca los precios, seguirá anexando "al plustrabajo una parte mayor de la jornada laboral que los demás capitalistas de su industria" ${ }^{45}$. Es decir, el mismo proceso por el que se abaratan las mercancías se acrecienta el plusvalor, razón por la cual el "capitalista, a quien solo le interesa la producción del valor de cambio, pugne constantemente por reducir el valor de cambio de las mercancías" "46 No obstante, que un "capitalista venda más significa que los otros capitalistas que ofertan el mismo producto van a vender menos, y en último extremo irán a la quiebra" ${ }^{47}$. Ello hace que el resto de los capitalistas se vean impelidos a introducir en sus procesos productivos una maquinaria similar o mejor. Una vez que se haya generalizado dicha maquinaria, el tiempo socialmente necesario para la producción de esas mercancías disminuirá, y correlativamente su valor. Ahora bien, si se abarata el valor de las mercancías, y dichas mercancías son necesarias para la subsistencia del obrero, el valor de la fuerza de trabajo se abaratará también. Esto es, el movimiento por el cual se abarata la mercancía es el mismo por el que se abarata al obrero. Y ello significa algo más, a saber, que el tiempo de trabajo necesario de la jornada laboral habrá disminuido $\mathrm{y}$, si ésta mantiene su duración, el tiempo de plustrabajo habrá aumentado ${ }^{48}$. Esto es el plusvalor relativo.

43 Conviene volver a matizar que el hecho de que un capitalista, con la esperanza de obtener un beneficio extra, decida ser innovador no es más que la expresión de una lógica cuyo verdadero sujeto es el valor en un proceso de valorización que no tiene fin. Precisamente por ello, el capitalista es el lugar donde el capital adquiere conciencia y voluntad.

$44 \quad$ Ibidem, p. 385

45 Ibidem, p. 387

Ibidem, p. 389.

47 M. Heinrich, op. cit., p. 149.

48 Si se quiere profundizar en el paradójico, incluso contradictorio, hecho de que el plusvalor aumente a base de que aquello que lo hace posible (fuerza de trabajo) disminuya, remitimos tanto a los planteamientos de R. Kurz y A. Jappe como a K. Marx, El capital, op. cit., p. 496 ss. 
Hasta ahora hemos dado cuenta de dos maneras por las cuales el valor se valoriza, a saber, mediante el alargamiento de la jornada laboral -y, correlativamente, del tiempo de plustrabajo-, y mediante la reducción del tiempo de trabajo necesario -manteniéndose constante la magnitud de la jornada laboral-. Quizá ahora podamos reparar en que, dado que el objetivo es la valorización del valor, "la naturaleza (...) y la fuerza de trabajo [son] un simple medio" ${ }^{49}$. No puede resultarnos extraño entonces que lo verdaderamente "antiecológico [sea] la esencia del capital, [en tanto que] constituye a la naturaleza y a la persona del trabajador como mediaciones para la «valorización del valor»" $"$. En efecto, "por su lógica interna, el capital es indiferente a la destrucción de los fundamentos naturales de la vida, del mismo modo que es indiferente a la destrucción de las fuerzas de trabajo"51. Ello quiere decir que, pese a que un capitalista individual repare en que obtiene beneficios a costa del tiempo de plustrabajo de la fuerza de trabajo, a costa del entorno natural o de seres vivos, dicha toma de conciencia no será suficiente para evitar o superar la lógica del valor que se valoriza, ni siquiera para que cambie su comportamiento en tanto que lugar donde el capital tiene conciencia y voluntad. Justamente por ello, creemos que este debe ser el marco de una filosofía de la ecología a la altura de nuestros días, una filosofía de la ecología que sea consciente de que la lógica del capital puede extenuar a la naturaleza y al ser humano. Una filosofía de la ecología, en definitiva, que no caiga en "la ingenuidad de algunos ecologistas que, con toda buena voluntad, hacen el juego al capital" 52 .

\section{Sobre el rendimiento de las categorías marxianas para una filosofía ecológica}

La producción capitalista no desarrolla la técnica y la combinación del proceso social de producción sino socavando al mismo tiempo los dos manantiales de toda riqueza: la tierra y el trabajador.

(Marx, El capital, Libro I)

Terminábamos el apartado anterior comentando que la comprensión de las formas absoluta y relativa de producir plusvalor constituía el marco, quizá necesario, sobre el cual plantear hipotéticamente una filosofía de la ecología a la altura de nuestros días. Y es que el plusvalor absoluto y relativo eran dos formas como se valorizaba el valor, ese proceso ilimitado que tiene lugar en un mundo limitado y que, pese a ser ejecutado por seres humanos, tiene como verdadero sujeto del proceso al valor. En este apartado vamos a poner de manifiesto lo que ha estado latiendo de fondo en este artículo, a saber, que la sociedad capitalista, al estar orientada a la producción de plusvalor, es depredadora con los seres vivos, el entorno natural y el trabajador. Empezaremos

\footnotetext{
M. Heinrich, op. cit., p. 159.

50 E. Dussel, Las metáforas teológicas de Marx, Navarra, Verbo Divino, 1993, p. 232.

1 M. Heinrich, op. cit., p. 159.

52 E. Dussel, Las metáforas teológicas de Marx, op. cit., p. 225.
}

viendo cómo atrofia, agota e incluso puede provocar la muerte prematura de la fuerza de trabajo prolongando e intensificando todo lo posible la jornada laboral, así como también busca reducir el valor de los medios de subsistencia de los trabajadores, influyendo en sus condiciones habitacionales y alimenticias de vida. Todo ello se da en un interesante paralelismo, nos recuerda Manuel Sacristán, con la depredación de la tierra en la agricultura capitalista, o con el sometimiento de determinadas especies animales a condiciones industriales de vida donde lo que se busca es una producción cada vez mayor e irrestricta.

La producción de plusvalor absoluto, si recordamos, giraba en torno a una prolongación de la jornada laboral posibilitada por la naturaleza del intercambio de la fuerza de trabajo por su equivalente, de donde no se desprendía límite alguno a su magnitud. El propio Marx nos comenta que en su época había jornadas laborales cuya duración, superior a doce horas, no solo impedía la vida hogareña y familiar, sino que además "minaba la salud del obrero y provocaba así una vejez y muerte prematuras" $" 53$.Acaso en la actualidad, tras el rótulo de nuevos emprendedores, no nos encontramos obreros que "alargan sin límites su jornada laboral o incluso se llegan reducir el salario hasta el límite de trabajar sin cobrar a cambio de formación" ${ }^{2}$ ? Ciertamente es posible que haya una legislación que asegure una duración normal de jornada laboral (como lo fue la ley fabril inglesa del 1833 a la que alude nuestro filósofo); sin embargo, hay algo preocupante que se pone, si cabe, aún mas de manifiesto en nuestra actualidad. Y es que dicha regulación se le presenta al capital como un límite externo a su valorización, un límite que, dado el caso, buscará traspasar. ¿Acaso no es un "claro fraude de ley obligar a los trabajadores a declararse autónomos para, así, contratar jurídicamente los «servicios de una empresa» en vez de a un «trabajador» (lo cual obligaría a respetar derechos laborales)" ${ }^{55}$ ?

De hecho, en una situación donde la duración de la jornada laboral está limitada externamente, la única forma como se puede valorizar el valor es aumentando la velocidad e intensidad del trabajo. Marx nos comenta que esta es la razón de fondo por la cual se obligaba a los herreros "a dar tantos golpes más, (...) a respirar tantas veces, (...) a incrementar su gasto vital en una cuarta parte [para] producir durante un período limitado una cuarta parte más de trabajo" "A6 . ¿Acaso actualmente no vemos cómo, con tal de evitar pérdidas monetarias, se termina incorporando el tiempo de las comidas "al proceso de producción mismo, de tal manera que al obrero se le echa comida como si él fuera un medio de producción más, como a la caldera carbón" ${ }^{57}$ ? Es más, Marx explica que en su época se llegaba a escamotear el tiempo que los obreros, especialmente niños, necesitaban de aire fresco y luz solar para su propio crecimiento, arguyendo que "la luz del gas que había en las fábricas era un

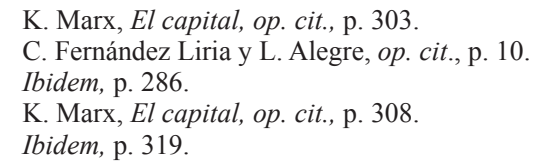


adecuado sustitutivo del sol"58. Ahora bien, ¿acaso esto no guarda relación con lo que ocurre, por ejemplo, en ciertos países del Sudeste Asiático?

Por otro lado, la maquinaria, aun siendo capaz de reducir el tiempo de trabajo socialmente necesario para la producción de mercancías, bajo condiciones capitalistas no es más que "el medio más poderoso de prolongar la jornada de trabajo más allá de todo límite natural" 59 . En efecto, ¿alguna vez nos hemos parado a pensar por qué si con la incorporación de una máquina se pueden producir más mercancías en menos tiempo, no se producen las mismas mercancías, pero en menos tiempo, pudiéndose generar tiempo libre? Sin embargo, la maquinaria bajo el mando de la lógica del capital pone las condiciones de su propia reproductibilidad: el que se produzca más en menos tiempo es un medio para trabajar aún más ${ }^{60}$.

Asimismo, en el apartado anterior comentábamos que una de las consecuencias de la producción del plusvalor relativo era el abaratamiento de las mercancías, un abaratamiento que de darse en aquellas mercancías básicas que constituyen el valor de la fuerza de trabajo se podría traducir un abaratamiento correlativo de esta última. Quizá no fuese casual que encontrásemos en la época de Marx pan vendido a medio precio, el cual estaba adulterado, de manera que los obreros "comían cierta cantidad de sudor humano, mezclado con (...) telarañas (...) y levadura alemana podrida, por no hablar del alumbre, la arenisca y otros ingredientes minerales igualmente apetitosos" $"$. Si dicho pan era vendido a medio precio y estaba adulterado era porque habían entrado en escena ciertos capitalistas que terminaban forzando a sus competidores a disminuir costes como fuera posible. Tal y como recuerda Manuel Sacristán, ¿acaso no ocurrió algo similar con los casos de intoxicaciones por aceite de colza en los años ochenta del siglo xx en España?

58 J. B. Foster, La ecología de Marx. Materialismo y naturaleza, Ulzama, Intervención cultural/El Viejo Topo, 2000, p. 175.

59 K. Marx, El capital, op. cit., p. 491.

60 Conviene matizar que Marx explica en ibidem, p. 453, nota al pie 89, que la tecnología pone al descubierto el comportamiento activo del hombre con respecto a la naturaleza, el proceso de producción inmediato de su existencia, sus relaciones sociales de vida, así como las representaciones intelectuales que surgen de ellas. Esto es, la maquinaria es elaborada como respuesta a una necesidad práctica en un contexto histórico determinado, el cual está caracterizado por unas relaciones sociales, unos procesos de trabajo y una relación con la naturaleza determinados. Esta totalidad de factores en mutua interacción que rodean la creación de la máquina son interiorizados por ella. Entiéndase bien, con interiorizar nos referimos a que un estudio sobre las tecnologías y formas organizativas capitalistas puede revelar mucho sobre la relación de dicha sociedad con la naturaleza. Así pues, quizá "no todo proceso de producción industrial se pueda desacoplar simplemente de su aplicación capitalista, para así desplegar súbitamente solo sus efectos beneficiosos" (M. Heinrich, op. cit., p. 160). Tal vez debamos replantearnos, tal y como recomienda Riechmann, el uso de determinada maquinaria o ciertas técnicas de producción capitalistas que han interiorizado la relación de dicha forma de sociedad con la naturaleza, o que han sido diseñadas para facilitar la autovaloración del capital. Nos estamos refiriendo a prácticas tales como "la pesca intensiva e industrial (responsable de la casi extinción de numerosas especies marinas), la tala total en las selvas tropicales incluso las centrales nucleares o la ganadería intensiva" (M. Löwy, Ecosocialismo. La alternativa radical a la catástrofe ecológica capitalista, Buenos Aires, El Colectivo, 2011, p. 34).

${ }_{61}$ K. Marx, El capital, op. cit., p. 300.
Respecto de las condiciones habitacionales de los barrios obreros, Marx, guiado por los análisis de Engels, convendrá que sus características principales eran el hacinamiento, mal saneamiento y la mala ventilación. En efecto, la creciente población urbana se acumulaba en grandes centros, lo cual estaba empezando a generar una ruptura entre el campo y la ciudad, una ruptura que terminaría perturbando el metabolismo entre el hombre y la tierra. Es John Bellamy Foster quien nos llama la atención sobre el uso que hace Marx de la noción de metabolismo (Stoffwechsel), enfatizando en el rendimiento que podemos extraer de su fractura como discernimiento de lo que se ha perdido en la sociedad capitalista y de lo que necesita ser recuperado.

Tal vez lo que se haya perdido en una sociedad dominada por la ley del valor que se valoriza es tiempo libre suficiente "para la educación humana, para el desenvolvimiento intelectual, para el desempeño de funciones sociales, para el trato social, para el libre juego de las fuerzas vitales físicas y espirituales"62. Quizá desde este marco podamos leer a Rachel Carson, la cual afirma que:

En el mundo moderno no hay tiempo. La rapidez del cambio y la velocidad con que se crean nuevas situaciones siguen al impetuoso y descuidado paso del hombre [o quizá debiéramos decir a la hambruna de plusvalor] más que al paso pausado de la naturaleza ${ }^{63}$.

Hemos traído a colación este fragmento, así como también escogíamos la preocupante afirmación marxiana que abría el presente apartado, para poner de manifiesto que una sociedad dominada por la ley del valor que se valoriza socava la fuerza de trabajo a la par que a los seres vivos y su entorno, y, lo que es más, parece que "no se extinguirá hasta haber destruido antes totalmente el metabolismo duradero entre la especie humana y la naturaleza" ${ }^{64}$. De hecho, Marx, siguiendo al economista político James Anderson, defenderá que la fertilidad del suelo, al variar históricamente, está experimentando un declive en la sociedad moderna capitalista por la acción humana ${ }^{65}$. Conjugando dichas ideas con las del químico Justus Liebig, el cual relacionaba el empobrecimiento del suelo con la ausencia de reciclado del estiércol, Marx enfatizará

\footnotetext{
Ibidem, p. 319
}

R. Carson, Primavera silenciosa, Barcelona, Crítica, 2019, p. 7.

64 M. Sacristán Luzón, Pacifismo, ecología y política alternativa, Barcelona, Icaria, 1987, p. 147.

65 Durante el siglo XIx la disminución de la fertilidad del suelo era una preocupación en la sociedad capitalista europea y norteamericana, que llevó en más de una ocasión al pánico y al consecuente aumento de la demanda de fertilizantes naturales como el guano peruano. Nótese bien, el pánico surgió ante la posibilidad de que no se valorizase el valor. La indiferencia del capital respecto a las condiciones de fertilidad del suelo se manifiesta al preferir la opción menos costosa, a saber, un fertilizante importado, antes que devolver a los campos las condiciones de su fertilidad, que, en el caso de Inglaterra terminaban en el río Támesis. Ello hace que Marx comente que "la misma rapacidad ciega que en un caso agota la tierra (...) [y] obliga a arrojar guano en los campos ingleses (...), en el otro habría hecho presa en las raíces de la fuerza vital de la nación. Las epidemias periódicas fueron aquí tan elocuentes como lo es en Alemania y Francia la estatura decreciente de los soldados" (K. Marx, El capital, op. cit., p. 287). 
en que "todo progreso de la agricultura capitalista no es solo un progreso en el arte de esquilmar al obrero, sino a la vez en el arte de esquilmar el suelo" ${ }^{\text {"66. Esta }}$ asociación directa realizada por el filósofo entre la explotación de la fuerza de trabajo y de la tierra anima a "iniciar una reflexión acerca de la articulación entre lucha de clases y defensa del medio ambiente, en un combate común contra la dominación del capital" ${ }^{67}$, contra su ratio. Justamente en esto consiste el ecosocialismo.

Tomando de Hegel la afirmación ácida y sarcástica de que en nuestra época razonadora hay buenas razones para todo lo que anda mal en el mundo, Marx pone de manifiesto las buenas razones, la lógica o ratio, que rigen la sociedad moderna capitalista. Ya sabemos que dicha lógica es la del valor que se valoriza, para lo cual necesita alargar, acelerar e intensificar la jornada laboral de su fuerza de trabajo, una fuerza de trabajo que opera sobre materiales proporcionados por el entorno natural. En efecto, el entorno, los seres vivos y la fuerza de trabajo son un mero medio para la producción ilimitada de plusvalor, de plusvalor con la forma de mercancías concretas (plusproducto). Precisamente por ello no debe extrañarnos que se necesiten consumir hoy más recursos naturales que ayer, que se llegue a arruinar la fertilidad del suelo si así obtiene un rendimiento acrecentado de él, o que se demande la "alteración genética de determinadas plantas y del uso más intensivo de productos químicos añadidos, tales como los pesticidas" $"$. Asimismo, tampoco debe sorprendernos la indiferencia de dicha lógica respecto del bienestar de los seres vivos, aun cuando en muchos casos se los someta a condiciones industriales de vida, donde no solo se les hacina y engorda, sino que se les llega a alterar la percepción del día y de la noche, a fin de obtener de ellos más recursos en menos tiempo.

En definitiva, es porque el proceso de valorización del valor es ilimitado, es porque "el capital no tiene ninguna posibilidad de establecerse a sí mismo un límite, pues toda limitación es su total aniquilación como capital"'69, por lo que creemos que se torna imperativo, teoréticamente, dejar sentadas las bases para una filosofía de la ecología consciente de que la lógica del valor que se valoriza es depredadora con la fuerza de trabajo, con los seres vivos y su entorno -donde incluiríamos suelo, aire y agua-. Y no solo eso, sino que como toda "práctica ecologista choca inmediatamente con el modo presente de producción"70, creemos que es imprescindible "mostrar a los grupos revolucionarios que tienen que ser ecologistas y a los ecologistas que tienen que ser socialmente revolucionarios" $" 71$. Dejamos, no obstante, como ardua y difícil tarea pendiente a la posteridad el dar con el mejor modo de hacerlo, sin caer en capitalismos verdes ni de rostro humano.

\section{Conclusiones}

Comenzábamos el artículo reflexionando sobre las determinaciones formales de la mercancía en tanto que las personas de la sociedad capitalista no se relacionaban entre sí de forma inmediatamente social, sino por la mediación de éstas. De esta forma, nos veíamos conducidos a afirmar que el valor no era más que la expresión de una sociabilidad que producían las personas, una sociabilidad donde operaba de facto una abstracción que vaciaba de contenido los trabajos concretos para posibilitar el intercambio. Asimismo, veíamos que la forma de expresión del valor más adecuada en una sociedad con intercambio generalizado era la forma de dinero, y reflexionando sobre sus funciones llegábamos al plusvalor. Con todo ello, queríamos poner de manifiesto que la lógica de la sociedad capitalista buscaba únicamente la producción continua e ilimitada de mercancías en tanto que plusproducto (plusvalor). Si terminábamos centrando nuestra atención en el plusvalor absoluto y relativo no era solo porque ponían de manifiesto dicha lógica, sino porque permitían desvelar lo que se oculta tras ella, a saber, el socavamiento de la fuerza de trabajo, del entorno natural y sus seres vivos. Y es que para que el valor pueda valorizarse, necesita tanto alargar e intensificar la jornada laboral como aumentar su demanda de recursos naturales, fertilizantes, pesticidas, hormonas destinadas al engorde... Terminábamos recalcando la necesidad teórica de dejar sentadas las bases de una filosofía de la ecología consciente de la rapacidad de la lógica del capital, así como la urgencia práctica de aunar las reivindicaciones ecológicas con las sociales.

\section{Bibliografía}

Carson, R., Primavera silenciosa, Barcelona, Crítica, 2019.

Dussel, E. Las metáforas teológicas de Marx, Navarra, Verbo Divino, 1993.

-, La producción teórica de Marx. Un comentario a los Grundrisse, Ciudad de México, Siglo XXI, 1985.

-, Hacia un Marx desconocido. Un comentario de los manuscritos 61-63, Ciudad de México, Siglo XXI, 1988.

Fernández Liria, C. y Alegre Zahonero, L., Marx desde Cero, para el futuro que viene, Madrid, Akal, 2018.

Foster, J.B., La ecología de Marx. Materialismo y naturaleza, Ulzama, Intervención cultural/El Viejo Topo, 2000.

Harvey, D., Guía para leer el Capital Libro I, Madrid, Akal, 2016.

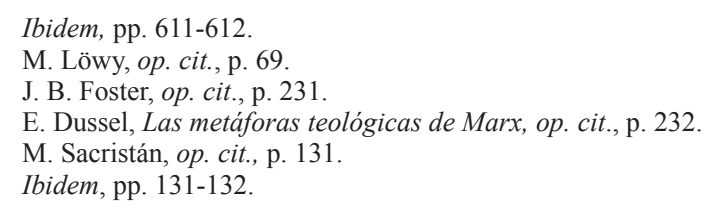


Heinrich, M., Crítica de la economía política: una introducción a El capital de Marx, Madrid, Escolar y Mayo, 2008.

Löwy, M., Ecosocialismo. La alternativa radical a la catástrofe ecológica capitalista, Buenos Aires, El Colectivo, 2011.

Lukács, G., "La cosificación y la consciencia del proletariado", Historia y consciencia de clase (vol. 2), Barcelona, Grijalbo, 1969, pp. 7-161.

Marx, K., El capital (tres libros, ocho vols.), Ciudad de México, Siglo XXI, 2019.

-, Elementos fundamentales para la crítica de la economía política, borrador 1857-1858(Grundrisse vol. 1), Ciudad de México, Siglo XXI, 2007.

Postone, M., Tiempo, trabajo y dominación social, Madrid, Marcial Pons, 2006.

Ruiz Sanjuán, C., Historia y sistema en Marx, Madrid, Siglo XXI, 2019.

Ramas San Miguel, C., Fetiche y mistificación capitalistas: la crítica de la economía política de Marx, Madrid, Siglo XXI, 2018.

Riechmann Fernández, J., El socialismo puede llegar solo en bicicleta, Madrid, La Catarata, 2012.

Sacristán Luzón, M., Pacifismo, ecología y política alternativa, Barcelona, Icaria, 1987. 